\title{
Management Practices and Breeding History of Varieties Strongly Determine the Fine Genetic Structure of Crop Populations: A Case Study Based on European Wheat Populations
}

\author{
Abdul Rehman Khan ${ }^{1,2}$, Isabelle Goldringer ${ }^{1, *(1)}$ and Mathieu Thomas $3,4, *$ (i) \\ 1 CNRS (Centre national de recherche scientifique), INRAE (Institut national de recherche pour l'agriculture, \\ l'alimentation et l'environnement), Université Paris-Saclay, AgroParisTech, GQE (Génétique quantitative et \\ évolution)-Le Moulon, 91190 Gif-sur-Yvette, France; arehman@cuiatd.edu.pk \\ 2 Department of Biotechnology, COMSATS (Commission on Science and Technology for Sustainable \\ Development in the South) University Islamabad, Abbottabad Campus, 22060 Abbottabad, Pakistan \\ 3 CIRAD (Centre de coopération internationale en recherche agronomique pour le développement), UMR \\ AGAP (Unité mixte de recherche en Amélioration génétique et adaptation des plantes méditerranéennes et \\ tropicales), F-34398 Montpellier, France \\ 4 AGAP (Amélioration génétique et adaptation des plantes méditerranéennes et tropicales), Univ Montpellier, \\ CIRAD (Centre de coopération internationale en recherche agronomique pour le développement), INRAE \\ (Institut national de recherche pour l'agriculture, l'alimentation et l'environnement), Montpellier SupAgro, \\ F-34000 Montpellier, France \\ * Correspondence: isabelle.goldringer@inrae.fr (I.G.); mathieu.thomas@cirad.fr (M.T.)
}

Received: 31 October 2019; Accepted: 24 December 2019; Published: 14 January 2020

check for updates

\begin{abstract}
As the effects of climate change begin to be felt on yield stability, it is becoming essential to promote the use of genetic diversity in farmers' fields. The presence of genetic variability in variety could fulfil this purpose. Indeed, the level of intra-varietal genetic diversity influences the spatio-temporal stability of yields and the disease susceptibility of crop species. Breeding history of varieties and their management practices are two factors that should influence intra-varietal genetic diversity. This paper describes the genetic diversity of eight wheat samples covering a gradient from modern single varieties to on-farm mixtures of landraces. This gradient discriminates between landrace, historical and modern varieties, considering the breeding history of varieties, between single-varieties and mixtures of varieties, and between ex situ and in situ de facto strategy in terms of management practices. Genetic diversity of these samples was analyzed with the help of 41 single nucleotide polymorphism markers located in neutral regions, through computing genetic indices at three different levels: Allelic, haplotypic and genetic group level. Population structure and kinship were depicted using discriminant analysis and kinship network analysis. Results revealed an increase in the complexity of the genetic structure as we move on the gradient of variety types (from modern single variety to in situ on-farm mixtures of landraces). For the landraces, the highest levels of genetic diversity have been observed for a landrace (Solina d'Abruzzo) continuously grown on-farm in the region of Abruzzo, in Italy, for many decades. This landrace showed an excess of haplotypic diversity compared to landraces or the historical variety that were stored in genebanks (ex situ conservation). Genetic analyses of the mixtures revealed that, despite a very high selfing rate in wheat, growing in evolutionary mixtures promotes recombination between different genetic components of the mixture, a second way to increase the level of haplotype diversity. When management practices such as growing in mixture and on-farm management are combined, they substantially increase the different levels of genetic diversity of the populations (allelic, haplotypic, genetic group diversity), and consequently promote their adaptability. Our results confirm the need to develop and manage evolving diversified large populations on-farm. These results invite crop diversity managers such as genebank curators, community seed bank managers and farmers' organizations to adapt their
\end{abstract}


management strategies to the type of variety they wish to manage, because we have shown that their choices have a strong influence on the genetic composition of the crop populations.

Keywords: intra-varietal genetic diversity; dynamic management; in situ conservation; ex situ conservation; on-farm management; Triticum aestivum. L.

\section{Introduction}

Since domestication and for thousands of years, crops have been grown as populations (i.e., landraces) and selected on-farm, therefore allowing among population (varietal) and within population (genetic) diversification. These two levels of diversity confer crop adaptability to contrasting environmental conditions and farmers' practices [1-4]. However, with the advancement of knowledge, especially in plant breeding and genetics (Mendelism, F1 hybrid development, pure line breeding, etc.), and modernization of agriculture from the middle of the nineteenth century in western countries, these genetically diverse landraces have been progressively replaced by genetically uniform modern varieties. This was particularly the case after the Second World War with the introduction of seed regulations such as distinctness, uniformity and stability (DUS) that a new variety had to meet to be registered and marketed [5]. The breeding history of varieties is thus really informative.

The increased use of genetically uniform crops since the Green Revolution has significantly improved yields and helped to alleviate the problem of hunger in the world. However, these modern varieties are highly dependent on inputs. The widespread use of these products in a context of climate change, water restrictions, pesticide resistance and rising prices for petroleum-derived chemicals is beginning to raise real concerns for society. One typical example of the impact of diseases on modern varieties is the corn leaf blight epidemics in America in 1970, which caused a 15\% reduction in the estimated production [6]. Similar events have been described in other studies [7-9]. In the case of oat, the impact of the disease was found to be $25 \%$ less for landraces than for modern varieties [10]. The causal relationship between genetic diversity and disease tolerance has been demonstrated for rice in China [11] showing a lower impact of plant disease for mixtures of varieties compared to single varieties. In some cases, higher robustness and stress tolerance have been observed due to genetic diversity and higher level of heterozygosity [12,13]. Mobilizing among-variety genetic diversity through mixtures and within-variety genetic diversity by growing landraces or population varieties has become more important than ever before with global climate change and thus the increased risk of environmental variability in the near future $[13,14]$.

These changes in the environmental conditions have made the conservation and use of genetic diversity crucially important. The scientific community has raised awareness about genetic erosion since the pioneer works accomplished by Vavilov or Harlan from the first part of the twentieth century [15]. Two types of conservation methods are generally employed for plant genetic resources: (i) Ex situ conservation and (ii) in situ conservation. Ex situ conservation is a static evolutionary strategy that involves the storage of samples (seeds, propagules and plants) outside their environment of origin such as in gene banks, botanical gardens, DNA banks, etc. [16-19]. In situ conservation is an evolutionary dynamic strategy in which genetic diversity is maintained in habitats where such diversity arose and continues to grow, i.e., for crop plants, in areas where that particular species has been domesticated and is continuously selected by farmers [20-22]. This in situ conservation is usually considered to be on-farm conservation (mainly landraces). This approach ensures the conservation of genetic diversity over time through the action of evolutionary forces (genetic drift, selection, mutation, migration) $[1,23]$. The adaptive response that a population shows when encountering a changing environment largely depends on the level and the structure of genetic diversity within the population $[24,25]$. 
Several studies were carried out in the recent past to understand the trends of crop genetic diversity in the last century. These studies generally neglected the within-variety (within-accession) diversity as they analysed very small sample sizes (1-5 individuals per landrace, accession or even species), and very often investigated either released varieties or ex situ conserved landraces [26-28]. Consequently, few studies have compared the effects of ex situ and in situ conservation on crop population genetic diversity. Sun et al. found higher genetic diversity and more alleles in landraces conserved in situ compared to the landraces conserved ex situ in rice [29]. Further, the evaluation of 600 landraces of rice conserved on-farm revealed that the genetic diversity was maintained even after 27 years strengthening the case of advantages of on-farm conservation [30]. In contrast, a decrease in genetic diversity due to genetic drift during regeneration with limited sample sizes in ex situ conservation has been shown in bean [31] and barley [32]. While $88 \%$ of total natural diversity was found in ex situ conserved Vatica guangxiensis [33], a better maintenance of genetic diversity of Parashorea chinensis was observed in in situ conservation than in ex situ conservation [34]. The effects of conservation of crop biodiversity by the two methods (in situ and ex situ) was studied in more detail by Negri and Tiranti [35], who identified reduced population size as the main factor causing the reduction of genetic variation, followed by ex situ multiplication, which increased subpopulation differentiation due to different environmental conditions compared to the adaptation area. In a recent study, the comparison of genetic diversity of rice landraces conserved ex situ in 1980 as well as conserved on-farm until 2014 showed that the on-farm conservation system maintained more alleles and higher genetic diversity compared to ex situ conserved landraces indicating that on-farm conservation provides the opportunity of evolution along with conservation [36]. Various other studies in crops species such as maize [1], rice [37], common bean [35], barley [32] and sorghum [38], have confirmed that in situ conservation, especially on-farm conservation, was highly capable of maintaining and enriching the within-population genetic diversity and heterozygosity. In these studies, diversity was found within each population cultivated under the name of a given landrace variety and to a lesser extent among those populations. Such heterogeneity is compatible with good productivity and quality under low input conditions, probably due to better local adaptation and more buffering capacity under stress conditions, as shown for instance in the case of an Italian landrace of celery [39].

Therefore, from a plant genetic resource management perspective, it is important to evaluate the effect of factors such as the mating system, the breeding history of the variety, the farmer's practices and the conservation strategies on the extent of the genetic population structure of varieties. We propose to describe the role of three of them: The breeding history of the variety, the conservation strategy and the population composition. Three modalities are considered for the breeding history of the varieties: Landraces, historical and modern varieties. Landraces are varieties developed by farmers before the 1850s. historical varieties were developed between the 1850s and the 1960s. Modern varieties are those developed since the 1960s. The conservation strategy discriminates ex situ conservation and in situ conservation. The composition of the population distinguishes between single varieties and mixtures.

In this study, using a set of eight populations of bread wheat (Triticum aestivum $\mathrm{L}$., $2 n=6 x=42$, AABBDD, self-pollinating species) with varying breeding histories and management practices (conservation and composition) provides an opportunity to understand the influence of all these three factors on population structure (Table 1). In such a set of populations, different genetic structures are expected to arise depending upon their history and farmer practices in the area. Based on our knowledge and the literature, we hypothesized that there was a gradient of increasing genetic diversity from modern varieties to mixture of landraces. This hypothesis was used to examine the diversifying processes in action in farmers' fields.

These eight populations (described in Table 1) were characterized using 41 neutral molecular markers. Genetic diversity was analysed at three levels: The allelic, haplotypes and genetic group level to search for a possible gradient within these eight populations. Additionally, the fine population structure of the different varieties has been revealed using a discriminant analysis and a kinship 
network analysis. The consequences of conservation and management methods on these different population structures are discussed in light of the different history of each variety and the genetic structure depicted in this study.

\section{Materials and Methods}

\subsection{Context of the Study}

The present study is based on the same sampling and experimental design described in Dawson et al. [40]. Seven farmer's varieties (three landraces, three mixtures, one historical variety) and one modern variety of bread wheat were selected for genotypic analysis (Table 1). Only one modern variety was sampled in this study as no genetic variation is expected for modern varieties since they are submitted to the distinction, uniformity and stability criteria to be marketed. The choice of these varieties was done by farmers on the basis of particular agronomic or quality traits, which they felt could be of interest for other organic farmers [41]. Seven organic farmers (four from France: JFB, FFM, HHF and VVC, two from the Netherlands: PVI and PVZ and one from Italy: GCX) were contacted through the partner organizations in the European Farm Seeds Opportunities project (http:/ / cordis.europa.eu/search/index.cfm?fuseaction=proj.document\&PJ_RCN=9643492) for this purpose. 
Table 1. Description of the eight wheat populations used in the experimental design (adapted from [40]).

\begin{tabular}{|c|c|c|c|c|c|}
\hline No & $\begin{array}{l}\text { Name } \\
\text { (abbr.) }\end{array}$ & $\begin{array}{l}\text { Type of Variety } \\
\text { (abbr.) }\end{array}$ & $\begin{array}{l}\text { Type of } \\
\text { Conservation } \\
\text { (abbr.) }\end{array}$ & $\begin{array}{l}\text { Farm (Country } \\
\text { of Origin) }\end{array}$ & $\begin{array}{l}\text { Description and Source of Original } \\
\text { Variety }\end{array}$ \\
\hline 1 & Renan (RN) & $\begin{array}{l}\text { Modern variety } \\
\text { (MV) }\end{array}$ & None & None & $\begin{array}{l}\text { Modern French variety (INRA). The most } \\
\text { common variety for organic farming in } \\
\text { France. }\end{array}$ \\
\hline 2 & $\begin{array}{l}\text { Haute Loire } \\
\text { (HL) }\end{array}$ & Landrace (LR) & ex situ (EX) & FM (France) & $\begin{array}{l}\text { Landrace from the mountainous region } \\
\text { in central France. Conserved ex-situ } \\
\text { in the French National Gene Bank. } \\
\text { Under on-farm cultivation since 2004, in } \\
\text { Northwestern France. }\end{array}$ \\
\hline 3 & Piave (PI) & Landrace (LR) & ex situ (EX) & GC (Italy) & $\begin{array}{l}\text { Landrace from Northern Italy. } \\
\text { Conserved ex-situ in Instituto di } \\
\text { Genetica e Sperimentazione Agronomica } \\
\text { di Vicenza, Italy, obtained from their } \\
\text { regional gene bank. }\end{array}$ \\
\hline 4 & $\begin{array}{l}\text { Rouge de } \\
\text { Bordeaux } \\
\text { (RB) }\end{array}$ & $\begin{array}{l}\text { historical } \\
\text { variety (HV) }\end{array}$ & in situ (IN) & JFB (France) & $\begin{array}{l}\text { historical Southwestern French variety } \\
\text { from the late } 1800 \text { 's. The initial sample } \\
\text { used in this experiment came from a } \\
\text { farming community in the Bordeaux } \\
\text { region and was never conserved ex-situ. }\end{array}$ \\
\hline 5 & $\begin{array}{l}\text { Solina } \\
\text { d'Abruzzo } \\
\text { (SO) }\end{array}$ & Landrace (LR) & in situ (IN) & TDS (Italy) & $\begin{array}{l}\text { Landrace from the mountainous region } \\
\text { in Central Italy. In continuous cultivation } \\
\text { in situ. }\end{array}$ \\
\hline 6 & $\begin{array}{l}\text { Zonne } \\
\text { hoeve (ZH) }\end{array}$ & $\begin{array}{l}\text { Mixture } \\
\text { modern } \\
\text { varieties } \\
\text { (MIXMV) }\end{array}$ & in situ (IN) & $\begin{array}{l}\text { PVI (The } \\
\text { Netherlands) }\end{array}$ & $\begin{array}{l}\text { Mixture of two modern German varieties } \\
\text { (Rektor and Bussard). Provided by } \\
\text { the farmer who cultivated these two as } \\
\text { mixture for more than ten years in the } \\
\text { central region of the Netherlands. }\end{array}$ \\
\hline 7 & $\begin{array}{l}\text { Melange de } \\
\text { Touselles } \\
\text { (TO) }\end{array}$ & $\begin{array}{l}\text { Mixture } \\
\text { landraces } \\
\text { (MIXLR) }\end{array}$ & in situ (IN) & HF (France) & $\begin{array}{l}\text { Farmer composed mixture from four } \\
\text { different landraces conserved ex situ: } \\
\text { Three T. aestivum and one T. turgidum } \\
\text { Conserved in situ for ten years. }\end{array}$ \\
\hline 8 & Redon (RD) & $\begin{array}{l}\text { Mixture } \\
\text { landraces } \\
\text { (MIXLR) }\end{array}$ & in situ (IN) & VC (France) & $\begin{array}{l}\text { Farmer composed mixture from seven } \\
\text { spikes, each from a different landrace } \\
\text { accession from the Redon region from } \\
\text { the French National Gene Bank and } \\
\text { conserved in situ for ten years. }\end{array}$ \\
\hline
\end{tabular}

Sample Description: Management Practices and Breeding History of Varieties

The eight varieties, chosen for the present study, represent different management practices and types of farmer varieties presented in Table 1. Management practices distinguished: (a) Whether farmers have grown these varieties in their fields for at least ten years (in situ) or they requested from ex situ gene-bank or seed trader within the five past years (ex situ); (b) whether the varieties are grown on their own in a field (single variety) or are grown in a mixture. We distinguished three types of breeding history of varieties: Landraces, historical varieties, and modern varieties.

\section{Ex situ conservation}

Three varieties of this study were managed following ex situ conservation practices. Renan (RN) is a French modern variety currently the most widely cultivated variety in organic agriculture in France. Farmers requested Haute-Loire (HL) and Piave (PI), two landraces from France and Italy ex situ gene-bank collections, respectively.

In situ conservation 
Five varieties were managed following in situ conservation practices. Rouge de Bordeaux (RB) is technically an historical variety from the late 1800 s but was never selected for genetic homogeneity and the sample used here came from a farming community near the Bordeaux region. Solina d'Abruzzo $(\mathrm{SO})$ is a landrace continuously cultivated in its region of origin in Italy. Zonnehoeve $(\mathrm{ZH})$ is a mixture of two modern varieties from 1980 to 1990, planted and harvested together over ten years on an organic farm in The Netherlands. Redon (RD) and Touselles (TO) are landraces from ex situ collections, reconstituted by farmers as mixtures of several distinct accessions with the same name in the gene bank. TO is particular because it has three T. aestivum components and one T. durum component. Both $\mathrm{RD}$ and TO have been cultivated about ten years on-farm $[4,40]$.

\subsection{Experimental Design}

In 2006, seeds needed for the experiment were sampled on the farms of origin (around $3 \mathrm{~kg}$ each). $\mathrm{RN}$ seed lot $(3 \mathrm{~kg}$ ) was obtained from INRA in 2006. An amount of 0.3 to $0.4 \mathrm{~kg}$ per variety per farmer depending on their seeding rate (between 250 to 500 seeds per $\mathrm{m}^{2}$ ) and on the varieties' thousand kernel weight was sent to each of these seven farms, mostly those of the farmers who provided varieties for sowing in 2006. For three years, the farmers multiplied each variety in two $10 \mathrm{~m}^{2}$ plot which were separated from other plots with a distance sufficient to prevent the sample mixing at harvest $($ see $[4,40]$ for more details). After three years of multiplications at these farms, the seed samples were collected to be used for genotypic analysis. After three years, only 48 of the 56 populations (eight varieties $x$ seven sites) were sampled. Unfortunately, eight seed lots could not be recovered due to experimental problems (five populations from JFB site and three populations from PVZ site). To improve the power of our analysis dealing with within-variety diversity, we added seed lots from the initial 2006 versions of each variety (eight initial varieties) for a total of 56 seed lots. Plants from each seed lot were sown in trays on the 16th of December 2010 at the rate of 30 individuals per population. The second leaf was sampled from each plant for DNA extraction.

\subsection{Molecular Analysis}

The DNA from each plant (30 plants per population and 56 populations) was separately extracted and genotyping of each sample (plant) was individually performed. For each plant, total DNA was extracted from $200 \mathrm{mg}$ of the second leaf through DNA adsorption on Whatman Unifilter plates by following a protocol derived from the DNeasy 96 Plant kit (QIAGEN, Valencia, CA, USA). The quantification of the extracted DNA was done using Nanodrop $\mathbb{R}$ (Thermo Scientific) and PicoGreen ${ }^{\mathrm{TM}}$ followed by photospectrometry. Then the DNA concentration was normalized to $20 \mathrm{ng} / \mu$ for each sample. KASPAR method (Kbioscience) was used to genotype 1650 individuals of 56 populations (around 30 individuals per population) with a 96 SNP array. For this genotyping, 46 neutral markers (SNP) were used. These 45 neutral markers (out of a 90 markers) were selected from wheat $9 \mathrm{~K}$ iSelect assay (http:/ / malt.pw.usda.gov/t3/sandbox/wheat/termsofuse.php) [42,43] after validation through genotyping of test individuals (preliminary genotyping with only 12 individuals) because they showed satisfying results, in terms of quality of genotyping, in the preliminary genotyping evaluation, had high diversity on the screening panel on the basis of Polymorphism Information Content value (PIC value), as well as evenly distributed across the genome (data not shown).

\subsection{Data Analysis}

Molecular analysis revealed that five neutral markers were of poor quality and therefore were discarded and 161 individuals were rejected as they had more than $15 \%$ of missing data. The genetic analysis of the samples was done based on 41 neutral markers using a panel of 1489 individuals.

\subsubsection{Within-Variety Allelic Diversity}

The mean observed heterozygosity $\left(H_{0}\right)$ was estimated for each sample. A genetic diversity $\left(H_{e}\right)$ index was estimated at three levels: (a) Allelic $\left(H_{e}(a)\right)$, (b) haplotypic $\left(H_{e}(h)\right)$ and (c) genetic group 
$\left(H_{e}(g g)\right) . H_{0}$ and $H_{e}(a)$, which is the unbiased Nei's genetic index, were estimated using the software GENETIX version 4.05.2 [44]. The haplotypic diversity index was estimated using the gene diversity formula in the software Arlequin [45] and the genetic group diversity index was estimated applying the Simpson index using Vegan [46], a package developed in R core [47].

\subsubsection{Haplotype Inference}

In order to study the fine genetic structure, imputation of missing data and haplotype phase detection was carried out with PHASE [48] by using the 1489 diploid individuals (corresponding to the pooled dataset) with the 41 neutral markers. Settings performed with PHASE were decided according to PHASE guideline recommendations [49] by using the MR4 algorithm and a numeric experiment based on a high quality subset of 300 individuals without any missing data. The quality of the imputation was controlled by simulating different rates of missing data within the high quality data subset. Based on this work, the analysis was performed with 100 burns-in periods before 100 iterations with 100 permutations per population and a recombination rate of 0.01 .

\subsubsection{Structure Analysis}

Genetic relationship among the eight samples of bread wheat was analyzed computing the Roger's distance between all pairs of samples using Adegenet [50], a package developed in R core [47]. A neighbor Joining dendrogram was generated to represent the relationship among these eight populations based on Roger's distance and using the R package Ape [51]. Bootstrap support was obtained for each node of the dendrogram out of 10,000 replicates.

The pairwise- $F_{S T}$ were computed to estimate genetic differentiation among the same populations using the R package Hierfstat [52]. The confidence interval was estimated for each pairwise- $F_{S T}$ value based on 1000 bootstrap replicates.

The organization of genetic diversity was studied using two methods: Discriminant analysis of principal components (DAPC) and kinship network analysis (KNA). They were employed on the new data set constituted of 397 distinct haplotypes after PHASE missing data imputation for the 41 neutral markers. For technical reasons, each haploid haplotype was converted into homozygous diploid.

The DAPC was done using the Adegenet package. This analysis was done in two steps on diploid haplotypes. First, a k-means procedure was applied to detect the optimal partition of the pooled haplotypes. The K-means algorithm was run with a number of clusters ranging from 1 to 60 , with 100,000 replicates for each value of $k$ and 30 different seeds. The Bayesian information criterion (BIC) was used. The optimal number of clusters $(\mathrm{k})$ is obtained for the smallest value of BIC. During a second step, a discriminant analysis was carried out on the dataset using the optimum number of clusters detected, providing a probability of assignation of each haplotype to each of the k groups. The genetic groups detected were named according to the corresponding variety when they were found to be representative of the considered farmer's varieties (FVs). All the haplotypes present in clusters others than their specific variety groups were considered as potential migrant or off-type haplotypes. Identification of potential migrants and off-types within populations was done on the basis of DAPC results. The haplotype of each of these potential migrants and off-types was compared one by one with the haplotypes of the same cluster and with the haplotypes of clusters assigned to their varieties, to decide their status as good genotypes or migrants. Only $142(9.5 \%)$ individuals were detected as migrants and removed from further analysis. DAPC analysis was done a second time on the refined dataset to check for the stability of the clustering.

Kinship network analysis (KNA) at the haplotype level provided a representation of the relationship among all 448 distinct haplotypes detected in the pooled dataset after missing data imputation and phasing. KNA was based on the kinship matrix, obtained after counting the number of shared alleles between all pairs of the 448 distinct haplotypes present in the dataset. Thresholds were applied at two levels to simplify the network representation while retaining the maximum level of information. Only haplotypes occurring more than once are represented by nodes. Two nodes 
(haplotypes) are connected if they share a minimum of $87 \%$ of their alleles. The same approach was used in [13]. In order to combine the results of both DAPC and KNA and to discuss the consistency of the two approaches, haplotypes (individuals) were color coded by DAPC cluster assignment. Then, in KNA each haplotype was represented using the same color to see whether haplotypes belonging to the same DAPC cluster showed a tendency to be more clustered in the KNA analysis.

\subsection{Off-Type Identification and Data Purification}

The discriminant analysis of principal component (DAPC) performed on 1489 individuals (2978 haplotypes) after missing data imputation, revealed an optimal number of clusters (genetic group) equal to 25 . Twenty-two genetic groups among the 25 corresponded mainly to one variety and were renamed according to this information, while three clusters shared individuals from two or more varieties and were therefore denoted as a Common Group (CG1, CG2, CG3) (Figure S1). This first analysis allowed us to identify two populations (RN and TO both cultivated in the farm called PVZ) which were not classified in their respective varietal group. RNPVZ belonged to one specific group with individuals only found in this population. TOPVZ belong to one of the groups specific for $\mathrm{RD}$. This was consistent with information from the person responsible for the experiment in FSO project saying that the farmer PVZ had difficulties in identifying some populations at harvest. For this reason, RNPVZ and TOPVZ were discarded from further analysis. In addition, 75 haplotypes were not assigned to their respective varietal groups, but instead were assigned to another genetic group. We also removed these individuals from the analysis, as we considered them as migrants from other varieties grown on the same farm. After this step of dataset cleaning, 310 distinct haplotypes were identified among 1325 individuals. DAPC was performed on this cleaned sub-dataset and the optimal number of genetic groups was $k=24$ (Figure S2).

\section{Results}

\subsection{Multi-Level Genetic Diversity and Population Structure of Samples}

Heterogeneous levels of neutral genetic diversity were found among the eight samples corresponding to different variety types (modern variety, historical varieties, landraces and mixtures) and different management strategies (ex situ vs in situ conservation and mono-varietal vs mixtures). The following sections provide a description of each sample using a multi-level analysis of the genetic diversity: the unbiaised Nei's diversity at the allelic $\left(H_{e}(a)\right)$, haplotype $\left(H_{e}(h)\right)$ and genetic group $\left(H_{e}(g g)\right)$ levels (Table 2).

Table 2. Summary of diversity indices computed for each of the eight samples of different variety types. $N$ : Sample size; $H_{0}$ : Observed heterozygosity; $R_{h}$ : Haplotypic richness; $H_{e}(a)$ : Unbiaised Nei's diversity index at the allelic level, $H_{\mathcal{e}}(h)$ : Diversity index at the haplotype level, $H_{e}(g g)$ : Diversity index at the genetic group level. NC stands for not conserved, EX for ex situ conserved, IN for in situ conserved, MV for modern variety, LR for landrace, HV for historical variety, MIXMV for mixture of modern varieties, MIXLR for mixture of landraces.

\begin{tabular}{cccccccccc}
\hline Number & Varieties & Variety Type & Conservation Type & $\boldsymbol{N}$ & $\boldsymbol{H}_{\boldsymbol{o}}$ & $\boldsymbol{H}_{\boldsymbol{e}}(\boldsymbol{a})$ & $\boldsymbol{R}_{\boldsymbol{h}}$ & $\boldsymbol{H}_{\boldsymbol{e}}(\boldsymbol{h})$ & $\boldsymbol{H}_{\boldsymbol{e}}(\mathrm{gg})$ \\
\hline 1 & RN & MV & NC & 165 & 0.0062 & 0.0057 & 3 & 0.2354 & 0.0000 \\
2 & HL & LR & EX & 165 & 0.0003 & 0.0012 & 5 & 0.0870 & 0.0000 \\
3 & PI & LR & EX & 165 & 0.0027 & 0.1046 & 41 & 0.4334 & 0.2315 \\
4 & RB & HV & IN & 172 & 0.0028 & 0.3364 & 37 & 0.6012 & 0.5713 \\
5 & SO & LR & IN & 206 & 0.0094 & 0.1607 & 192 & 0.9850 & 0.7497 \\
6 & ZH & MIXMV & IN & 154 & 0.0030 & 0.1642 & 23 & 0.8685 & 0.4347 \\
7 & TO & MIXLR & IN & 145 & 0.0042 & 0.3025 & 61 & 0.9340 & 0.7283 \\
8 & RD & MIXLR & IN & 153 & 0.0040 & 0.3364 & 35 & 0.9301 & 0.7414 \\
\hline
\end{tabular}




\subsubsection{Single Variety Conserved Ex Situ and Modern Variety}

Genetic diversity analysis revealed similar characteristics for one of the two landraces, "Haute Loire" (HL), which is managed as a single variety and conserved ex situ, and the modern variety, Renan. The other landrace (Piave) showed a contrasted pattern. "Haute Loire" was the most homogeneous sample with a single genetic group (Figure 1) denoted as "HL1". Consistently HL had a very low genetic diversity at the genetic group level $\left(H_{e}(g g)=0.000\right.$ (Table 2), but also at the allelic level $\left(H_{e}(a)=0.0012\right)$ and haplotypic level $\left(H_{e}(h)=0.0870\right)$. We noticed that the observed heterozygosity was also an order of magnitude lower in this sample than in the others $\left(H_{0}=0.0003\right.$ compared to $0.03<H_{0}<0.09$ for the others).

Similar to HL, all the individuals from the modern variety Renan (RN) were also characterized to have a unique genetic group named "RN1" (Figures 1 and S2). Moreover, the very low genetic diversity at all the three levels $\left(H_{\mathcal{e}}(a)=0.0057, H_{\mathcal{e}}(h)=0.2354\right.$ and $\left.H_{\mathcal{e}}(g g)=0.000\right)$ indicated very low within-population genetic diversity.

Piave (PI) the second ex situ landrace clearly showed a different pattern of genetic diversity and ultimately different genetic structure compared to the two previous samples. PI showed higher genetic diversity values at the allelic level $\left(H_{e}(a)=0.1046\right.$, haplotypic level $H_{e}(h)=0.4334$ and genetic group level $H_{e}(g g)=0.2315$ (Table 2$)$ than the two other samples. PI was a composite variety with two specific groups denoted PI1 and PI2 (Figure 1).

\subsubsection{Single Variety Conserved In Situ (HV and LR)}

The Rouge de Bordeaux (RB) variety showed a composite structure with three genetic groups (Figure 1), i.e., two main specific groups (RB1 and RB2) and one shared group (CG1) with Redon. In addition, genetic diversity at allelic, haplotypic and genetic group levels were relatively high for $\mathrm{RB}\left(H_{e}(a)=0.3364, H_{e}(h)=0.6012\right.$ and $H_{e}(g g)=0.5713$, respectively, Table 2) compared to the previously discussed varieties.

Solina d'Abruzzo (SO) also had a composite population structure with four specific genetic groups (SO1, SO2, SO3, SO4) and one shared group (CG2) with Touselles (Figure 1) indicating highly complex population structure. Interestingly, the probability that some individuals of this landrace fall in one specific group was relatively weak, but they always fall in groups specific to this landrace or in the CG2 group. A high level of genetic diversity at the haplotypic and genetic group levels was observed for SO $\left(H_{e}(h)=0.9850\right.$ and $H_{e}(g g)=0.7497$, respectively, Table 2$)$, but a relatively low allelic diversity $\left(H_{e}(a)=0.1607\right)$ was observed compared to RB. 


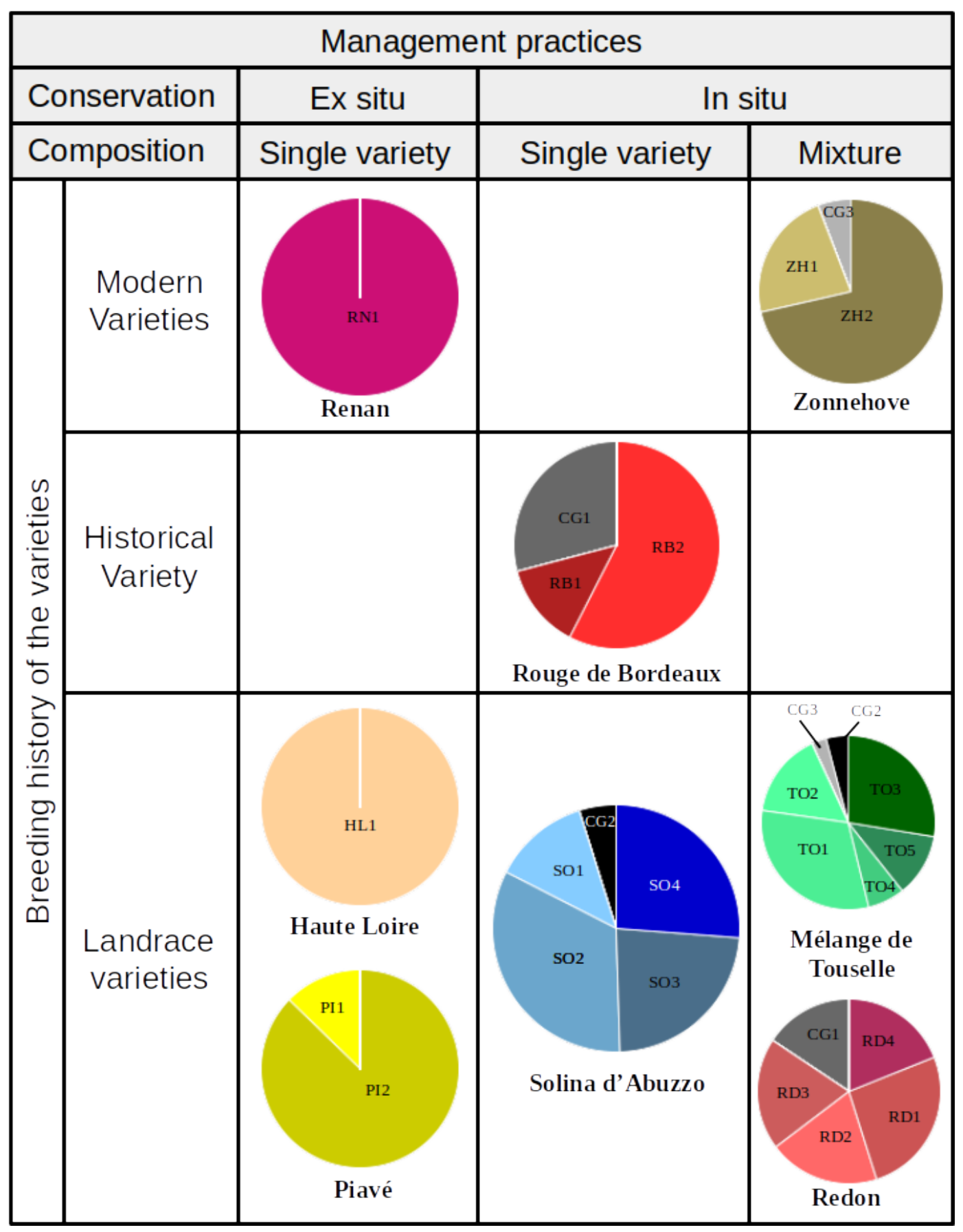

Figure 1. Genetic groups of each farmer variety after discarding the migrants $(N=1325)$. The size of the pie chart is proportional to the number of individuals from each variety used in the analysis, and different colors represent the proportion of individuals from a particular genetic group present in a farmer variety. HL1, PI1, PI2, RB1, RB2, RD1, RD2, RD3, RD4, SO1, SO2, SO3, SO4, TO1, TO2, TO3, TO4, TO5, ZH1 and ZH2 are the genetic groups specific to their corresponding farmer's variety as indicated by their initials. CG1, CG2 and CG3 are the are the genetic groups shared by two or more farmer's varieties.

\subsubsection{Mixtures In Situ Conserved (MIXMV and MIXLR)}

Zonne Hoeve $(\mathrm{ZH})$ was structured into two main fixed groups (ZH1 and $\mathrm{ZH} 2)$ and one shared group (CG3) with Touselles. ZH2 represented almost $75 \%$ of the mixture, explaining the relatively low genetic group diversity $H_{e}(g g)=0.4347$ observed for a mixture. The allelic diversity and haplotypic diversity $\left(H_{e}(a)=0.1642, H_{e}(h)=0.8685\right)$ were also intermediate (Table 2 ). 
The "Touselles" (TO) sample was composed of five main specific groups (TO1, TO2, TO3, TO4 and TO5) and two groups (CG2 and CG3) shared, respectively, with SO and ZH (Figure 1), consistent with the expectation that this mixture would have a complex population structure based on its history. A high level of genetic diversity was observed for the different genetic indices: $H_{e}(a)=0.3025$, $H_{e}(h)=0.9340$ and $H_{e}(g g)=0.7283$ indicating that the TO population was genetically diverse (Table 2).

Similar to TO, Redon (RD) also presented a composite structure with four main specific groups (RD1, RD2, RD3 and RD4) and one group (CG1) shared with RB (Figure 1). Genetic diversity indices were relatively high at the three levels: $H_{e}(a)=0.3364, H_{e}(h)=0.9301$ and $H_{e}(g g)=0.7414$ confirming the diverse nature of this population (Table 2).

\subsubsection{Relationship among Genetic Indices}

The correlations between $H_{e}(a)$ and $H_{e}(h)$ was significant and positive (Figure 2A, $p$-value $=<0.05, \hat{Y}=0.30+1.89 \hat{X})$. The correlations between $H_{\mathcal{e}}(a)$ and $H_{\mathcal{e}}(g g)$ was also significant and posotive (Figure $2 \mathrm{~B}, p$-value $<0.01, \hat{Y}=0.08+2.02 \hat{X}$ ).

However, some samples like RB, $\mathrm{ZH}$ and $\mathrm{SO}$ were relatively far from the regression line (Figure 2). For RB, an excess of allelic diversity, deficit of haplotypic diversity, and excess of genetic group diversity was observed compared to the other samples. $\mathrm{ZH}$ showed an excess of haplotype diversity and a deficit of allelic diversity and genetic group diversity compared to the other samples. SO showed an excess of haplotypic and genotype group diversity and a deficit of allelic diversity compared to the other samples.
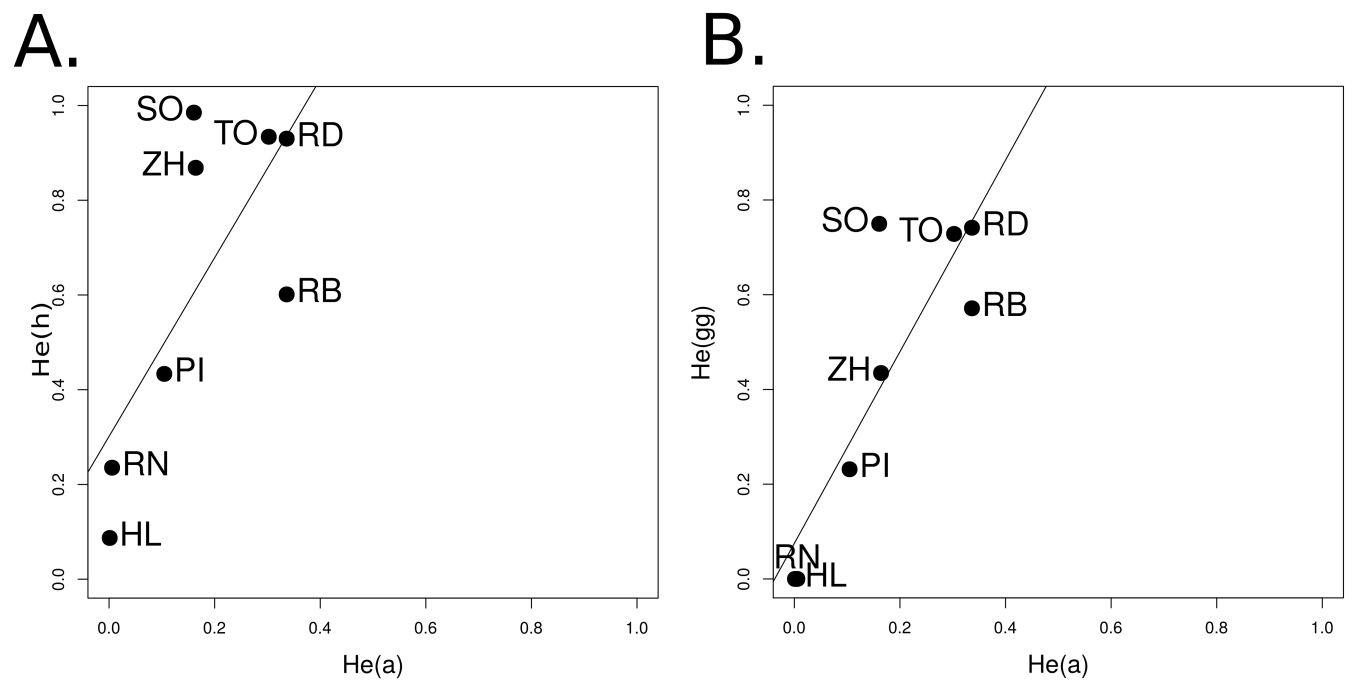

Figure 2. Relationship between genetic indices: (A) Between allelic diversity $\left(H_{\mathcal{e}}(a)\right)$ and haplotypic diversity $\left(H_{\mathcal{e}}(h)\right)(\mathrm{P}$-value $<0.05, \hat{Y}=0.30+1.89 \hat{X}) ;(\mathbf{B})$ between allelic diversity $H_{\mathcal{e}}(a)$ and genetic group diversity $\left(H_{\mathcal{e}}(g g)\right)(\mathrm{P}$-value $<0.01, \hat{Y}=0.08+2.02 \hat{X})$.

\subsection{Deciphering the Varietal Relatedness}

Dendrogram confidently separated the eight populations into three clusters (bootstrap support of $100 \%$, Figure 3). The first one is composed of $\mathrm{ZH}$ and PI which are themselves relatively different $\left(D_{\text {Rodger }}=0.46\right.$, bootstrap support equal to $\left.68 \%\right)$. The second cluster grouped RD and RB, two closed varieties $\left(D_{\text {Rodger }}=0.17\right)$ which are distinguished with intermediate confidence (bootstrap support equal to $50 \%$ ). The third group is composed of $\mathrm{TO}, \mathrm{SO}, \mathrm{RN}$ and $\mathrm{HL}$ in which varieties cannot be clearly distinguished (bootstrap support $<50 \%$ ) even if their genetic distances ranged from 0.14 to 0.53 . RN is the most distant population compared to the other populations, then it is ZH and PI. RN and PI are the two far populations $\left(D_{\text {Rodger }}=1.00\right)$. 


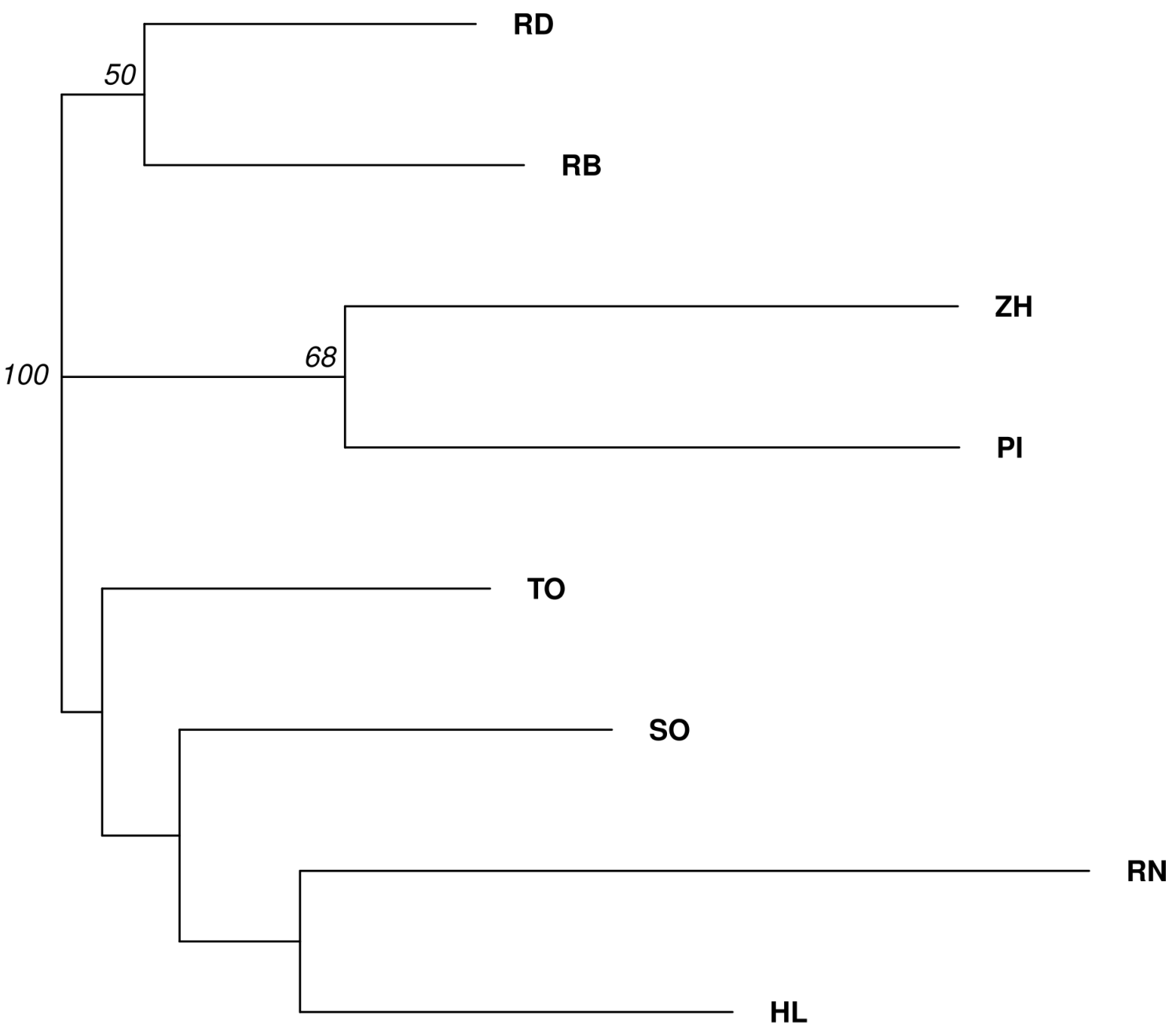

Figure 3. Neighbor joining dendrogram generated from Roger's distance on eight varieties of bread wheat described in Table 1. Node labels represent boostrap support $(>50 \%)$ out of 10,000 bootstrap replicates.

Pairwise-FST provided additional information (Table S1). Very strong differentiation was observed between the two varieties which are almost fixed: HL and RN, with a pairwise-FST close to 1 . Strong genetic differentiation was observed for pairs involving one of these two varieties with pairwise-FST ranging from 0.74 to 0.92 . Intermediate pairwise- $F S T$ values ranging from 0.73 to 0.64 , were observed when populations with a limited amount of genetic diversity such as $\mathrm{PI}, \mathrm{SO}$ and $\mathrm{ZH}$ were involved. The lowest differentiation values were observed when one or both populations were genetically diverse with a pairwise-FST ranging from 0.25 to 0.63 .

The kinship network analysis performed on 245 haplotypes after filtering (KNA, Figure 4) revealed that: (1) Genetic groups from the same variety were not always strongly related, and (2) genetic groups from two different varieties could be related.

$h 156$ and $h 40$, the two main haplotypes from the modern variety RN were only related to each other. The main haplotype from PI2 genetic group, $h 22$, was related to few haplotypes belonging to the same genetic group and not connected to the other haplotypes, indicating that this component of Piave variety was genetically very different from the rest. $h 362$, the main haplotype of the PI1 genetic group was connected to haplotypes belonging to several TO genetic groups, revealing that the PI1 genetic group appeared to be more related to TO rather than to its second genetic group PI2. $h 1$ was the main 
haplotype of the HL variety. It showed some relatedness with different haplotypes from several TO genetic groups and with only one SO haplotype (h305), respectively.

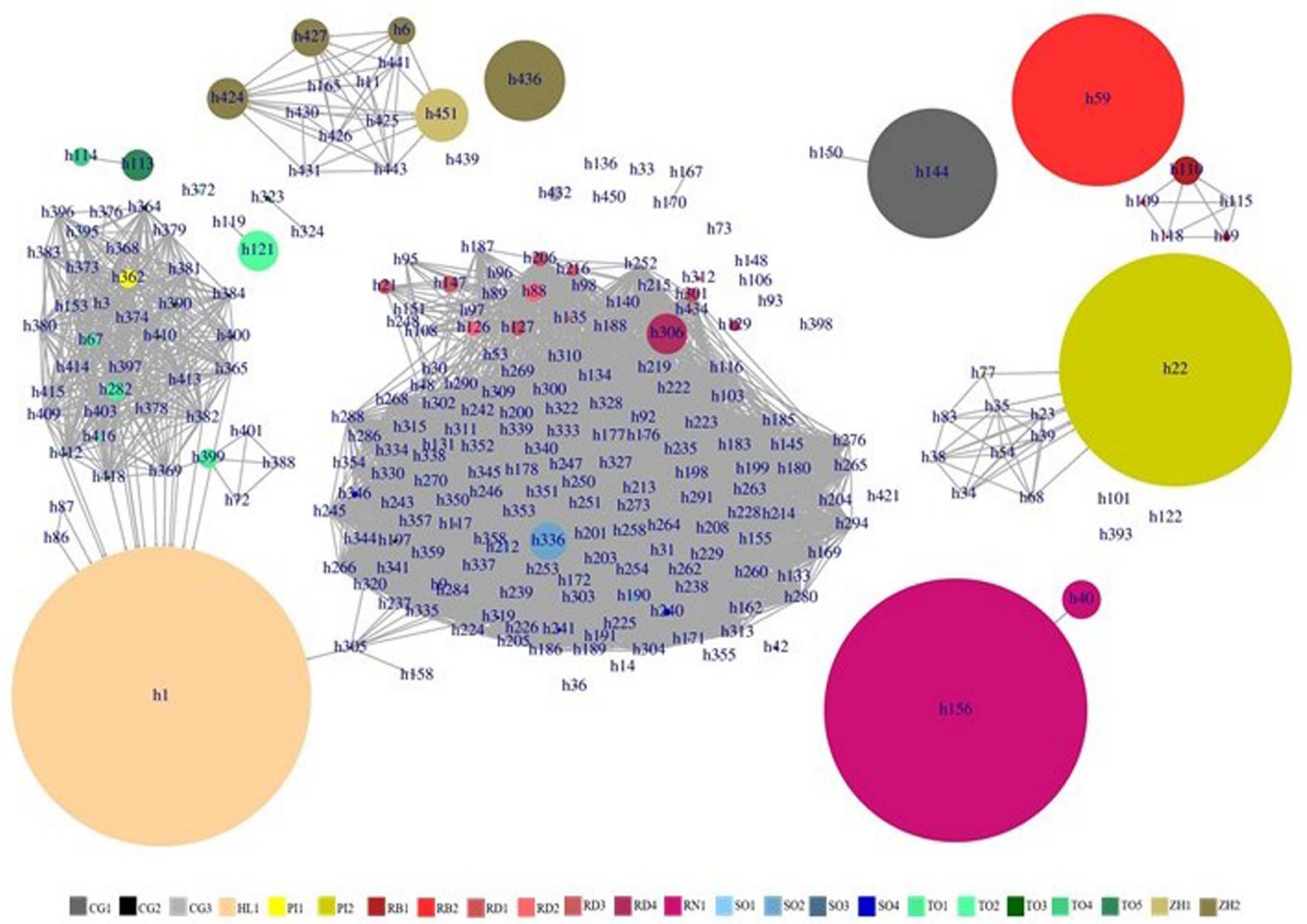

Figure 4. Kinship network representing all the individuals sampled over the eight varieties. Nodes are haplotypes that appeared more than once ( 245 over the 397 distinct haplotypes). Two haplotypes are connected if they share a minimum of $87 \%$ of alleles ( 34 over 41 markers). The color of the nodes reflects membership in one of the 24 genetic groups detected in DAPC analysis. The size of the node is proportional to the number of times this haplotype is observed in the sample (from 2 to 325 times).

The KNA analysis confirmed the composite characteristic of the mono-varietal in situ conserved $\mathrm{FV}$, (RB and SO). $h 110$ was the main haplotype of RB which was present in the genetic group RB1 and was connected to the other haplotypes present in this genetic group. $h 59$ haplotype, the main haplotype of genetic group RB2, was not connected to other haplotypes, showing a clearly distinct genetic make-up compared to other haplotypes from RB, as well as other samples. $h 144$ belonging to the CG1 genetic group was the same haplotype detected in RB and RD. This haplotype seemed very distinct from the other genetic groups. The landrace variety SO showed the most diverse population structure compared to other samples investigated in this experiment. Many haplotypes with mostly very low haplotypic frequencies were observed. Interestingly, most of these haplotypes were connected together, revealing a very strong relatedness among them. $h 336$ was the main and the most central haplotype within SO.

As expected, mixtures showed a high haplotypic diversity. For $\mathrm{ZH}, h 436$, the main haplotype of genetic group $\mathrm{ZH} 1$ was not connected to the other haplotypes of its genetic group, appearing to be weakly related to the rest of $\mathrm{ZH}$ as well as of other FV. $h 451$, the main haplotype of $\mathrm{ZH} 2$ was connected with haplotypes belonging the $\mathrm{ZH} 1$ genetic group. $h 432$ is the main $\mathrm{ZH}$ haplotypes assigned to the CG3 genetic group. The other ones were more related to $\mathrm{ZH} 1$ and $\mathrm{ZH} 2$.

Among different genetic groups of the RD mixture, the main haplotypes assigned to RD1 and RD2 like $h 126, h 127, h 147$ or $h 21$ were strongly related as the make a cluster. They were weakly connected with SO haplotypes. By contrast, the main haplotypes from the genetic group RD3 and RD4 like $h 206$ or $h 216$ showed a strong genetic relatedness with haplotypes of SO. The KNA applied to the TO mixture revealed that TO1 was very distinct from rest of the genetic groups as $h 121$, the main haplotype of 
this genetic group, was not connected to any other haplotype except $h 119$. The genetic groups TO3 and TO4 were composed by only one haplotype (respectively, $h 114$ and $h 113$ ). These two haplotypes were related to each other, but were not connected to the rest. The different haplotypes belonging to genetic group TO2 were connected to each other, as well as to the $h 362$ (the main haplotype of PI1 genetic group as described above). In addition, they were also connected with some other haplotypes belonging to TO5 genetic group indicating that TO2 was genetically more related to TO5 as compared to other genetic groups of TO.

\section{Discussion}

This investigation was designed to test the basic hypothesis that farmers' varieties are more genetically diverse than a modern commercial variety using bread wheat as case study. From this, the exploration of a range of intermediate situations has revealed that certain practices such as on-farm dynamic management of crop diversity or the cultivation of variety mixtures foster genetic diversification in the fields by allowing evolutionary mechanisms to occur.

\subsection{Diversifying Practices Interacting with the History of Varieties}

When grown as single varieties, the modern variety Renan (RN) and the two conserved ex situ landrace varieties (Piave, PI and Haute-Loire, HL) showed the lower levels of genetic diversity (allelic, haplotypic and for the genotypic groups), HL showing the lowest values for the three diversity indicators. These results are in line with previous studies that have identified that gene bank practices during regeneration may promote genetic drift [32] and selection [53], which induce a loss of genetic diversity. This is due to the constraints related to the large number of accessions that need to be regenerated each year and therefore the small amount of time and space that may be devoted to each accession and to the field conditions that may generate selective pressures.

By contrast, in situ on-farm management of crop diversity in farmers' fields by growing and harvesting a very large number of plants (usually $200-500$ seeds $/ \mathrm{m}^{2}$ over more than $10,000 \mathrm{~m}^{2}$ ) every year for a very long time fosters accumulation of genetic diversity in single varieties as observed for $\mathrm{RB}$ and SO. Indeed, these management practices should limit genetic drift and favor the emergence of new alleles by mutation and of new genotypes by recombination, even though outcrossing rate is low but not null in bread wheat [54]. Homozygous lineages are generally observed in such situation with a limited number of haplotypes that can reach a high frequency [55-57]. This interpretation is consistent with the historical variety (RB) which showed an excess of allelic diversity (0.33) but a deficit of haplotype diversity (0.60) indicating that only a few haplotypes are dominating. This phenomenon leading to a limited number of frequent haplotypes could be reinforced by a few bottlenecks in the past of this population. Such demographic event is consistent with available information about RB as it was selected in the 1850s from another historical variety called Noé before being widely grown in France at the end of the nineteenth century.

However, it was not quite the case for Solina (SO), a landrace continuously grown in the Abruzo area, Italy, which showed an excess of haplotype diversity (0.98) together with a moderate allelic diversity (0.16). While the allelic diversity of Solina seemed to be at the lower end of the range found in the literature for on-farm managed bread wheat landraces (for instance, $H_{e}(a)$ ranged from 0.17 to 0.34 in three bread wheat landraces collected in Oman in 2001 [58], haplotypic diversity clearly seemed extremely high. This makes it complicated to explain the particular pattern of genetic diversity structure found for SO. While natural selection due to the somewhat stressful conditions encountered in this region could drastically reduce genetic effective size as demonstrated in experimental wheat populations conducted under in station dynamic management $[59,60]$ and therefore impact the allelic diversity, the haplotypic genetic diversity would also be much reduced, which is not the case for SO. In addition, the populations conducted in experimental dynamic management over 10 to 20 generations probably do not represent the evolutionary dynamics of a landrace such as Solina, that has been managed on-farm for several hundred years, under conditions that we may imagine stable, and 
therefore probably relatively adapted to its local environment. One hypothesis is that recombination played a non-negligible role in the evolution of SO population structure which is in line with the trend found by Jullien et al. [56] who investigated the effects of the selfing rate, population genetic effective size and migration rate using a population genetic simulation model. However, although decreasing selfing led to a greater number of multilocus genotypes (i.e., a larger $H_{\mathcal{e}}(h)$ ), the range of values does not seem compatible with Solina's diversity pattern. In-depth investigating of more contrasted situations with higher seed migration together with selection and recombination in this area is essential to further clarify the mechanisms and evolutionary forces at work.

The same level of allelic genetic diversity was observed in the field when farmers decided to create mixtures compared to the level of allelic genetic diversity estimated for on-farm single varieties (an average of 0.26 compared to an average of 0.24 , respectively). However, more interestingly, the mixture of modern varieties, Zonne Hoeve $(\mathrm{ZH})$, showed a slight excess of haplotype diversity compared to the other mixtures (Figure 2A). This finding can be interpreted as an increase in effective recombination for a mainly selfing species. Year after year of cultivation including seed saving and seed replanting, a population may accumulate a few recombining plants between the two components of the mixture while the allelic diversity is still relatively limited because it is a mixture between two modern varieties genetically homogeneous.

Therefore, two practices can be considered as diversifying: (1) When farmers create mixtures of varieties, (2) when they grow a population for a long time in the same area such in the case of SO. The combination of the two practices, making mixture of landraces, leads to higher levels of allelic and haplotypic diversity, as we observed in TO and RD.

\subsection{Genetic Relatedness between Different European Farmer's Varieties}

Structure analysis of the eight varieties/mixtures of bread wheat showed strong genetic distance and pairwise- $F_{S T}$ between HL and RN which is consistent with the absence of genetic variability within each of these samples with a very limited number of shared alleles. By contrast, intermediate genetic distance and pairwise- $F_{S T}$ were observed between historical variety, landraces and landrace mixtures grown on-farm. This indicated that genetic variance is available and that a large part of alleles are shared among these heterogeneous varieties or mixture.

In previous studies, Thomas et al. [13,57] have shown that clustering methods usually used to analyse population structure are not fully adapted to detect the fine structure of crop populations with heterogeneous levels of genetic diversity. Results from a multivariate decomposition (DAPC) and a kinship network analysis, also known as haplotypic network, were combined to avoid the limitations of each analysis.

Our results confirmed the composite nature of variety mixtures such as $\mathrm{ZH}$, TO or RD as they were composed of three to seven genetic groups. These groups should correspond to the different components of the mixtures. More surprisingly, the same pattern was observed in two landraces (PI and $\mathrm{SO}$, Figure 1) and the historical variety (RB). This composite nature was previously reported in detail for RB [57] and TO [13] using SSR markers. This structural feature is thus independent of the type of markers used to analyse the genetic polymorphism of crop populations.

A focus on the genetic relationship among these composite populations reveals an unexpected situation: Two genetic groups belonging to two different varieties could be more related than two genetic groups from the same varieties. As already mentioned in a study describing TO [13], this reflects an overlapping genetic structure between certain varieties and could explain the lack of bootstrap support when genetic distance is computed among SO, TO, HL and RN, for instance, even if they are relatively distant and differentiated. It was also the case for Piave as its two genetic groups (PI1 and PI2) were not closely related, whereas PI1 and several genetic groups from TO were relatively closer (Figure 4). In addition, some genetic groups of TO were also related to the unique genetic group of HL. The same trend was observed between RB and RD, and between RD and SO. These results suggest that the western Europe landraces studied here shared, to some extent, a common 
genetic background which is still partially present within on-farm landraces and evolutionary mixtures. This highlights the existing porosity between these European landraces due to their common long term history which was progressively erased by human activity inducing strong discontinuity. These remnants of common genetic background are thus still available and can be used by farmers and breeders and adapted to different environmental conditions to face recent threats induced by climate change and other stressful phenomenon.

\section{Conclusions}

In this paper, we considered different crop varieties and mixtures of bread wheat ex situ conserved or continuously grown in situ on-farm. Our results revealed an increase in the complexity of genetic structure as we move on the gradient of variety types (from modern single variety to in situ on-farm mixtures of landraces). We have shown that two on-farm management practices increased genetic diversity: Mixtures of varieties and in situ on-farm management of landraces. When these management practices are combined, they substantially increase the different levels of genetic diversity of the populations (allelic, haplotypic, genetic groups diversity), and consequently improve their adaptability.

Indeed, genetic analyses of the mixtures revealed that, despite a very high selfing rate in wheat, growing in evolutionary mixtures promotes recombination between different genetic components of the mixture, a second way to increase the level of haplotype diversity. More surprisingly, an excess of haplotype diversity compared to the level of allelic diversity was observed for Solina d'Abruzzo (SO) in Italy, one of the landraces continuously cultivated in situ on-farm. Different evolutionary mechanisms have already been proposed to describe distribution of genetic diversity in self-pollinated species, but none of them is sufficient to explain the distribution observed in SO. The most likely scenario to explain such an organization of genetic diversity is a very large effective size through collective management by local farmers that combines seed circulation with mixing and selection of their seeds in addition to natural selection. These practices promote recombination between different genotypes and the fixation of neutral and adaptive mutations. In-depth investigation by simulation and experimentation is needed to decipher precisely the evolutionary mechanisms in action which allowed such features to emerge.

All these findings confirm the need to develop and manage evolving diversified large populations on-farm. In an era of global climate shift, where modern varieties have shown low adaptive potential to changing environmental conditions, especially in organic and low input areas, the use of highly diverse landraces and historical varieties in mixtures could solve the problem to a certain extent because on-farm diversified populations have a higher potential to adapt to their local environment than uniform varieties. Such diversifying practices need to be generalized, in particular when promoting agroecological and sustainable agriculture. The new EU seed legislation on heterogeneous material in 2018 is opening new opportunities in this direction. However, the evolutionary characteristics of these populations are still poorly understood by researchers and need to be better considered in the future.

Our conclusions invite crop diversity managers such as genebank curators, community seed bank managers and farmers' organizations to adapt their management strategies to the type of variety they wish to manage, because we have shown that their choices have a strong influence on the genetic composition of the crop populations.

Supplementary Materials: The following are available online at http:/ /www.mdpi.com/2071-1050/12/2/613/s1, Figure S1 : Distribution of the 1489 genotypes, Figure S2 : Distribution of the 1325 genotypes, Table S1 : Pairwise $F_{S T}$ computed between the 8 sample populations.

Author Contributions: A.R.K. conceptualized the study, devised the methodology, conducted the investigation, curated the data, performed formal analysis and drafted the original manuscript. I.G. conceptualized and supervised the study, devised and validated the methodology, acquired funding, administered the project, provided resources and, reviewed and edited the manuscript. M.T. supervised the study, devised and validated the methodology, visualized, reviewed and edited the manuscript.

Funding: This research was funded by a Specific Targeted Research Project of the European Commission Sixth Framework Program Priority 8.1 SSP: Opportunities for farm seed conservation, breeding and production 
Proposal/Contract no.: SSP-CT-2006-044345NAME. This study also received funding from the European Community's Seventh Framework Programme (FP7/ 2007-2013) under the Grant Agreement n245058-Solibam (Strategies for Organic and Low-input Integrated Breeding and Management). The PhD thesis of A.R.K. was supported by the Higher Education Commission (HEC) of Pakistan.

Acknowledgments: The authors thank E. Serpolay-Besson and J. Dawson for sharing seed lots studied in this paper and the information associated to them, S. Jouanne and N. Galic for their help in plant material growth, C. Remoué and X. Raffoux for DNA extractions, S. Thépot and J. Enjalbert for their help in selecting SNP markers. We are also thankful to the GQE - Le Moulon, INRA, Univ. Paris-Sud, CNRS, AgroParisTech, Université Paris-Saclay, Gif-sur-Yvette, 91190, France for providing the necessary lab facilities to conduct this investigation. The authors also thank J. Dawson for correcting the English language. We are also grateful to the three anonymous reviewers for their valuable comments on the original manuscript.

Conflicts of Interest: The authors declare no conflict of interest.The funders had no role in the design of the study; in the collection, analyses, or interpretation of data; in the writing of the manuscript, or in the decision to publish the results.

\section{References}

1. Louette, D.; Charrier, A.; Berthaud, J. In situ conservation of maize in Mexico: Genetic diversity and maize seed management in a traditional community. Econ. Bot. 1997, 51, 20-38. doi:10.1007/BF02910401. [CrossRef]

2. Elias, M.; Penet, L.; Vindry, P.; McKey, D.; Panaud, O.; Robert, T. Unmanaged sexual reproduction and the dynamics of genetic diversity of a vegetatively propagated crop plant, cassava (Manihot esculenta Crantz), in a traditional farming system. Mol. Ecol. 2001, 10, 1895-1907. doi:10.1046/j.0962-1083.2001.01331.x. [CrossRef] [PubMed]

3. Jarvis, D.; Brown, A.H.D.; Cuong, P.H.; Collado-Panduro, L.; Latournerie-Moreno, L.; Gyawali, S.; Tanto, T.; Sawadogo, M.; Mar, I.; Sadiki, M.; et al. A global perspective of the richness and evenness of traditional crop-variety diversity maintained by farming communities. Proc. Natl. Acad. Sci. USA 2008, 105, 5326-5331. doi:10.1073/pnas.0800607105. [CrossRef] [PubMed]

4. Dawson, J.C.; Goldringer, I. Breeding for genetically diverse populations: Variety mixtures and evolutionary populations. In Organic Crop Breeding; van Bueren, E.T.L., Myers, J.R., Eds.; John Wiley \& Sons: Chichester, UK, 2012; pp. 77-98.

5. Bonneuil, C.; Thomas, F. Gènes, pouvoirs et profits : La Recherche Publique dans les Transformations des Régimes de Production des Savoirs en Génétique Végétale de Mendel aux OGM; QUAE/FPH: Paris, France 2009.

6. Bent, A.F. Crop diseases and strategies for their control. In Plants, Genes and Crop Biotechnology, Chrispeels, M.J., Sadava, D.E., Eds.; Jones and Bartlett Publishers: Sudbury, MA, USA, 2003; pp. 390-414.

7. Harlan, J.R. Genetics of Disaster 1. J. Environ. Qual. 1972, 1, $212-215$. doi:10.2134/jeq1972.00472425000100030002x. [CrossRef]

8. Trenbath, B.R. Interactions Among Diverse Hosts and Diverse Parasites. Ann. New York Acad. Sci. 1977, 287, 124-150. doi:10.1111/j.1749-6632.1977.tb34236.x. [CrossRef]

9. Juska, A.; Busch, L.; Tanaka, K. The Blackleg Epidemic in Canadian Rapeseed as a "Normal Agricultural Accident". Ecol. Appl. 1997, 7, 1350-1356. doi:10.1890/1051-0761(1997)007[1350:TBEICR]2.0.CO;2. [CrossRef]

10. Sánchez-Martín, J.; Rispail, N.; Flores, F.; Emeran, A.A.; Sillero, J.C.; Rubiales, D.; Prats, E. Higher rust resistance and similar yield of oat landraces versus cultivars under high temperature and drought. Agron. Sustain. Dev. 2016, 37, 3. doi:10.1007/s13593-016-0407-5. [CrossRef]

11. Zhu, Y.; Chen, H.; Fan, J.; Wang, Y.; Li, Y.; Chen, J.; Fan, J.; Yang, S.; Hu, L.; Leung, H.; et al. Genetic diversity and disease control in rice. Nature 2000, 406, 718-722. doi:10.1038/35021046. [CrossRef]

12. de Vallavieille-Pope, C. Management of disease resistance diversity of cultivars of a species in single fields: Controlling epidemics. Comptes Rendus Biol. 2004, 327, 611-620. doi:10.1016/j.crvi.2003.11.014. [CrossRef]

13. Thomas, M.; Thépot, S.; Galic, N.; Jouanne-Pin, S.; Remoué, C.; Goldringer, I. Diversifying mechanisms in the on-farm evolution of crop mixtures. Mol. Ecol. 2015, 24, 2937-2954. doi:10.1111/mec.13214. [CrossRef]

14. Olesen, J.E.; Trnka, M.; Kersebaum, K.C.; Skjelvåg, A.O.; Seguin, B.; Peltonen-Sainio, P.; Rossi, F.; Kozyra, J.; Micale, F. Impacts and adaptation of European crop production systems to climate change. Eur. J. Agron. 2011, 34, 96-112. doi:10.1016/j.eja.2010.11.003. [CrossRef]

15. Frankel, O.; Bennett, E. Genetic Resources in Plants: Their Exploration and Conservation; Number 11 in International Biological Programme Handbook, Blackwell: Oxford, UK, 1970. 
16. Simmond, N.W. Variability in crop plants, its use and conservation. Biol. Rev. 1962, 37, 422-465. [CrossRef]

17. Henry, J.P.; Pontis, C.; David, J.; Gouyon, P.H. An experiment on dynamic conservation of genetic resources with metapopulations. In Species Conservation: A Population-Biological Approach; Seitz, A., Loeschcke, V., Eds.; CAB International: Basel, Switzerland, 1991; pp. 185-198.

18. Callow, J.A.; Ford Lloyd, B.V. Biotechnology and Plant Genetic Resources: Conservation And Use; Vol. Biotechnology in Agriculture Series: 19; CAB International: Wallingford, UK, 1997.

19. Wolfe, M.; Baresel, J.; Desclaux, D.; Goldringer, I.; Hoad, S.; Kovacs, G.; Löschenberger, F.; Miedaner, T.; Østergård, H.; Lammerts van Bueren, E. Developments in breeding cereals for organic agriculture. Euphytica 2008, 163, 323-346. doi:10.1007/s10681-008-9690-9. [CrossRef]

20. Pistorius, R. Scientists, Plants and Politics: A History of the Plant Genetic Resources Movement; International Plant Genetic Resources Institute: Rome, Italy, 1997.

21. Fowler, C.; Hawtin, G.C.; Hodgkin, T. Foreword. In Genes in the Field: On-farm Conservation of Crop Diversity; Brush, S., Ed.; International Plant Genetic Resources Institute; International Development Research Centre; Lewis Publishers: International Development Research Centre, Ottawa, Canada: 2000.

22. Raggi, L.; Ciancaleoni, S.; Torricelli, R.; Terzi, V.; Ceccarelli, S.; Negri, V. Evolutionary breeding for sustainable agriculture: Selection and multi-environmental evaluation of barley populations and lines. Field Crop. Res. 2017, 204, 76-88. doi:10.1016/j.fcr.2017.01.011. [CrossRef]

23. Hodgkin, T.; Rana, J.; Tuxill, J.; Balma, D.; Mar, I.; Karamura, D.; Valdivia, R.; Collado, L.; Latournerie, L.; Sadiki, M.; et al. Seed systems and crop genetic diversity in agroecosystems. In Managing Biodiversity in Agricultural Ecosystems; Jarvis, D., Padoch, C., Cooper, H.D., Eds.; CABI Publishing: Rome, Italy, 2007; pp. 77-116.

24. Mercer, K.L.; Perales, H.R. Evolutionary response of landraces to climate change in centers of crop diversity. Evol. Appl. 2010, 3, 480-493. doi:10.1111/j.1752-4571.2010.00137.x. [CrossRef] [PubMed]

25. Barrett, R.D.; Schluter, D. Adaptation from standing genetic variation. Trends Ecol. Evol. 2008, 23 , 38-44. doi:16/j.tree.2007.09.008. [CrossRef] [PubMed]

26. van de Wouw, M.; van Hintum, T.; Kik, C.; van Treuren, R.; Visser, B. Genetic diversity trends in twentieth century crop cultivars: A meta analysis. Theor. Appl. Genet. 2010, 120, 1241-1252. doi:10.1007/s00122-009-1252-6. [CrossRef]

27. Roussel, V.; Leisova, L.; Exbrayat, F.; Stehno, Z.; Balfourier, F. SSR allelic diversity changes in 480 European bread wheat varieties released from 1840 to 2000. Theor. Appl. Genet. 2005, 111, 162-170. doi:10.1007/s00122-005-2014-8. [CrossRef]

28. Jones, H.; Civáň, P.; Cockram, J.; Leigh, F.J.; Smith, L.M.; Jones, M.K.; Charles, M.P.; Molina-Cano, J.L.; Powell, W.; Jones, G.; et al. Evolutionary history of barley cultivation in Europe revealed by genetic analysis of extant landraces. BMC Evol. Biol. 2011, 11, 320. doi:10.1186/1471-2148-11-320. [CrossRef]

29. Sun, J.C.; Cao, G.L.; Ma, J.; Chen, Y.F.; Han, L.Z. Comparative genetic structure within single-origin pairs of rice (Oryza sativa L.) landraces from in situ and ex situ conservation programs in Yunnan of China using microsatellite markers. Genet. Resour. Crop. Evol. 2012, 59, 1611-1623. doi:10.1007/s10722-011-9786-2. [CrossRef]

30. Cui, D.; Li, J.; Tang, C.; Xinxiang, A.; Yu, T.; Ma, X.; Zhang, E.; Cao, G.; Xu, F.; Qiao, Y.; et al. Diachronic analysis of genetic diversity in rice landraces under on-farm conservation in Yunnan, China. Theor. Appl. Genet. 2016, 129, 155-168. doi:10.1007/s00122-015-2617-7. [CrossRef] [PubMed]

31. Gómez, O.J.; Blair, M.W.; Frankow-Lindberg, B.E.; Gullberg, U. Comparative study of common Bean (Phaseolus vulgaris L.) landraces conserved ex situ in Genebanks and in situ by farmers. Genet. Resour. Crop. Evol. 2005, 52, 371-380. doi:10.1007/s10722-005-2249-x. [CrossRef]

32. Parzies, H.K.; Spoor, W.; Ennos, R.A. Genetic diversity of barley landrace accessions (Hordeum vulgare ssp. vulgare) conserved for different lengths of time in ex situ gene banks. Heredity 2000, 84, 476-486. doi:10.1046/j.1365-2540.2000.00705.x. [CrossRef] [PubMed]

33. Li, Q.; Xu, Z.; He, T. Ex situ genetic conservation of endangered Vatica guangxiensis (Dipterocarpaceae) in China. Biol. Conserv. 2002, 106, 151-156. doi:10.1016/S0006-3207(01)00240-3. [CrossRef]

34. Li, Q.; He, T.; Xu, Z. Genetic evaluation of the efficacy of in situ and ex situ conservation of Parashorea chinensis (Dipterocarpaceae) in Southwestern China. Biochem. Genet. 2005, 43, 387-406. doi:10.1007/s10528-005-6778-y. [CrossRef] [PubMed] 
35. Negri, V.; Tiranti, B. Effectiveness of in situ and ex situ conservation of crop diversity. What a Phaseolus vulgaris L. landrace case study can tell us. Genetica 2010, 138, 985-998. doi:10.1007/s10709-010-9485-5. [CrossRef] [PubMed]

36. Wang, Y.; Wang, Y.; Sun, X.; Caiji, Z.; Yang, J.; Cui, D.; Cao, G.; Ma, X.; Han, B.; Xue, D.; et al. Influence of ethnic traditional cultures on genetic diversity of rice landraces under on-farm conservation in southwest China. J. Ethnobiol. Ethnomed. 2016, 12, 51. doi:10.1186/s13002-016-0120-0. [CrossRef]

37. Tin, H.; Berg, T.; Bjørnstad, A. Diversity and adaptation in rice varieties under static (ex situ) and dynamic (in situ) management. Euphytica 2001, 122, 491-502. doi:10.1023/A:1017544406975. [CrossRef]

38. Deu, M.; Sagnard, F.; Chantereau, J.; Calatayud, C.; Vigouroux, Y.; Pham, J.L.; Mariac, C.; Kapran, I.; Mamadou, A.; Gérard, B.; et al. Spatio-temporal dynamics of genetic diversity in Sorghum bicolor in Niger. Theor. Appl. Genet. 2010, 120, 1301-1313. doi:10.1007/s00122-009-1257-1. [CrossRef]

39. Torricelli, R.; Tiranti, B.; Spataro, G.; Castellini, G.; Albertini, E.; Falcinelli, M.; Negri, V. Differentiation and structure of an Italian landrace of celery (Apium graveolens L.): Inferences for on farm conservation. Genet. Resour. Crop. Evol. 2013, 60, 995-1006. doi:10.1007/s10722-012-9896-5. [CrossRef]

40. Dawson, J.C.; Serpolay, E.; Giuliano, S.; Schermann, N.; Galic, N.; Berthellot, J.F.; Chesneau, V.; Ferté, H.; Mercier, F.; Osman, A.; et al. Phenotypic diversity and evolution of farmer varieties of bread wheat on organic farms in Europe. Genet. Resour. Crop. Evol. 2013, 60, 145-163. doi:10.1007/s10722-012-9822-x. [CrossRef]

41. Serpolay, E.; Dawson, J.C.; Chable, V.; Bueren, E.L.V.; Osman, A.; Pino, S.; Silveri, D.; Goldringer, I. Diversity of different farmer and modern wheat varieties cultivated in contrasting organic farming conditions in western Europe and implications for European seed and variety legislation. Org. Agric. 2011, 1, 127-145. doi:10.1007/s13165-011-0011-6. [CrossRef]

42. Akhunov, E.D.; Akhunova, A.R.; Anderson, O.D.; Anderson, J.A.; Blake, N.; Clegg, M.T.; Coleman-Derr, D.; Conley, E.J.; Crossman, C.C.; Deal, K.R.; et al. Nucleotide diversity maps reveal variation in diversity among wheat genomes and chromosomes. BMC Genom. 2010, 11, 702. doi:10.1186/1471-2164-11-702. [CrossRef] [PubMed]

43. Chao, S.; Dubcovsky, J.; Dvorak, J.; Luo, M.C.; Baenziger, S.P.; Matnyazov, R.; Clark, D.R.; Talbert, L.E.; Anderson, J.A.; Dreisigacker, S.; et al. Population- and genome-specific patterns of linkage disequilibrium and SNP variation in spring and winter wheat (Triticum aestivum L.). BMC Genom. 2010, 11, 727. doi:10.1186/1471-2164-11-727. [CrossRef]

44. Belkhir, K.; Borsa, P.; Chikhi, L.; Raufaste, N.; Bonhomme, F. GENETIX 4.05, logiciel sous Windows TM pour la génétique des populations; ScienceOpen, Inc.: Burlington, MA, USA, 2004.

45. Excoffier, L.; Lischer, H.E.L. Arlequin suite ver 3.5: A new series of programs to perform population genetics analyses under Linux and Windows. Mol. Ecol. Resour. 2010, 10, 564-567. doi:10.1111/j.1755-0998.2010.02847.x. [CrossRef]

46. Oksanen, J.; Blanchet, F.G.; Friendly, M.; Kindt, R.; Legendre, P.; McGlinn, D.; Minchin, P.R.; O’Hara, R.B.; Simpson, G.L.; Solymos, P.; et al. Vegan: Community Ecology Package; R package version 2.5-5, 2019.

47. R Core Team. R: A Language and Environment for Statistical Computing; R Foundation for Statistical Computing: Vienna, Austria, 2018.

48. Stephens, M.; Smith, N.J.; Donnelly, P. A new statistical method for haplotype reconstruction from population data. Am. J. Hum. Genet. 2001, 68, 978-989. doi:10.1086/319501. [CrossRef]

49. Garrick, R.; Sunnucks, P.; Dyer, R.J. Nuclear gene phylogeography using PHASE: Dealing with unresolved genotypes, lost alleles, and systematic bias in parameter estimation. BMC Evol. Biol. 2010, 10, 118. doi:10.1186/1471-2148-10-118. [CrossRef]

50. Jombart, T.; Devillard, S.; Balloux, F. Discriminant analysis of principal components: A new method for the analysis of genetically structured populations. BMC Genet. 2010, 11, 94. doi:10.1186/1471-2156-11-94. [CrossRef]

51. Paradis, E.; Schliep, K. ape 5.0: An environment for modern phylogenetics and evolutionary analyses in R. Bioinformatics 2018, 35, 526-528. [CrossRef]

52. Goudet, J.; Jombart, T. Hierfstat: Estimation and Tests of Hierarchical F-Statistics; R package version 0.04-22; 2015. 
53. van Hintum, T.; van de Wiel, C.; Visser, D.; van Treuren, R.; Vosman, B. The distribution of genetic diversity in a Brassica oleracea gene bank collection related to the effects on diversity of regeneration, as measured with AFLPs. TAG Theor. Appl. Genet. 2007, 114, 777-786. doi:10.1007/s00122-006-0456-2. [CrossRef]

54. Enjalbert, J.; Goldringer, I.; David, J.L.; Brabant, P. The relevance of outcrossing for the dynamic management of genetic resources in predominantly selfing Triticum aestivum L. (bread wheat). Genet. Sel. Evol. 1998, 30, S197. doi:10.1186/1297-9686-30-S1-S197. [CrossRef]

55. Siol, M.; Prosperi, J.; Bonnin, I.; Ronfort, J. How multilocus genotypic pattern helps to understand the history of selfing populations: A case study in Medicago truncatula. Heredity 2008, 100, 517-525. doi:10.1038/hdy.2008.5. [CrossRef] [PubMed]

56. Jullien, M.; Navascués, M.; Ronfort, J.; Loridon, K.; Gay, L. Structure of multilocus genetic diversity in predominantly selfing populations. Heredity 2019, 123, 176-191. doi:10.1038/s41437-019-0182-6. [CrossRef] [PubMed]

57. Thomas, M.; Demeulenaere, E.; Dawson, J.C.; Khan, A.R.; Galic, N.; Jouanne-Pin, S.; Remoue, C.; Bonneuil, C.; Goldringer, I. On-farm dynamic management of genetic diversity: The impact of seed diffusions and seed saving practices on a population-variety of bread wheat. Evol. Appl. 2012, 5, 779-795. doi:10.1111/j.1752-4571.2012.00257.x. [CrossRef]

58. Zhang, P.; Dreisigacker, S.; Buerkert, A.; Alkhanjari, S.; Melchinger, A.E.; Warburton, M.L. Genetic diversity and relationships of wheat landraces from Oman investigated with SSR markers. Genet. Resour. Crop. Evol. 2006, 53, 1351-1360. doi:10.1007/s10722-005-4675-1. [CrossRef]

59. Enjalbert, J.; Dawson, J.C.; Paillard, S.; Rhoné, B.; Rousselle, Y.; Thomas, M.; Goldringer, I. Dynamic management of crop diversity: From an experimental approach to on-farm conservation. Comptes Rendus Biol. 2011, 334, 458-468. doi:16/j.crvi.2011.03.005. [CrossRef]

60. Raquin, A.L.; Depaulis, F.; Lambert, A.; Galic, N.; Brabant, P.; Goldringer, I. Experimental estimation of mutation rates in a wheat population with a gene genealogy approach. Genetics 2008, 179, 2195 -2211. doi:10.1534/genetics.107.071332. [CrossRef]

(C) 2020 by the authors. Licensee MDPI, Basel, Switzerland. This article is an open access article distributed under the terms and conditions of the Creative Commons Attribution (CC BY) license (http:/ / creativecommons.org/licenses/by/4.0/). 